\title{
CONGENITAL DISLOCATION OF THE HIP IN THE NEWBORN
}

\author{
G. B. Smaill, Wellington, New Zealand
}

Though it has long been recognised that the earlier treatment for congenital dislocation of the hip is started the better is the result, it is only quite recently that serious efforts have been made to recognise the condition at birth. A clinical method of diagnosing congenital dislocation of the hip first described by Ortolani (1937) has been used in Northern Italy for many years, but until von Rosen (1962) published his results only lip service was paid elsewhere to the diagnosis of hip dislocation in the newborn. Even now most orthopaedic textbooks emphasise only the classical signs of congenital dislocation of the hip and if it is mentioned at all Ortolani's test is usually described incorrectly.

In New Zealand it has been the practice in a few hospitals for all newborn babies to be examined for hip dislocation as part of a general physical examination. This examination is carried out by a variety of examiners, some more skilled than others. All babies in this country are born in maternity hospitals varying in size from about twelve beds to the larger units attached to general hospitals. Most of these babies are delivered by general practitioners and there is a wide variation in the number of deliveries each doctor does in a year and in the thoroughness of the examination of the babies delivered by him.

The present study was made of babies born in the maternity unit attached to Wellington Hospital. Fourteen per cent of these babies were delivered by members of the obstetric unit, the remainder by forty-five different doctors. Those deliveries done by the obstetric unit were either in unbooked cases or where some complication had arisen in pregnancy or labour necessitating specialist obstetrical management.

From February 1963 to April 1966 the author personally examined the hips of all 6,000 babies born at this hospital. For the first 2,100 babies clinical examination of the hips was carried out once weekly, so the babies ranged in age from none to seven days. In the first few months of the survey it was the author's policy to defer examination when a baby appeared to be very frail or ill until its condition had improved. As will be seen later, this proved to be unwise. The later 3,900 babies were seen at examinations conducted twice weekly, so that the babies ranged in age from none to four days.

\section{METHOD OF EXAMINATION}

The examination was carried out with the baby lying on its back in its cot with its nappies removed. To prevent cross infection the hands were washed between each examination. The techniques used were those described by Barlow (1962), with slight modification, and Ortolani (1937). Each hip of each baby was checked by the two methods. Though these methods have been fully described elsewhere, no apology is made here for outlining once again the steps of the examination.

Barlow's method-The left hip is examined first with the right hand. The baby's pelvis is supported with the thumb of the left hand on the pubis and the sacrum resting in the palm, the flexed right leg being tethered in the web space between thumb and index finger. The baby's left knee and hip are flexed to 90 degrees with the shin resting in the web space between thumb and index finger of the right hand. The right thumb rests on the medial aspect of the thigh in the region of the lesser trochanter while the fingers rest on the greater trochanter. The femur is in fact held firmly between fingers and thumb. Now pressure is exerted backwards with the thumb and at the same time the hand is slightly pronated. If the hip joint is lax the 
head of the femur is felt to slip out of the acetabulum. By pressing forward with the fingers and supinating the hand the head of femur is felt to slip back into the acetabulum. The test is then carried out on the right hip using the left hand to examine the hip while the right hand supports the pelvis.

This test is a very useful screen for detecting the lax or unstable hip. If the baby is quiet it is very simple but when the baby is crying muscle spasm sometimes makes it difficult to displace an unstable hip and more care is needed. It is, therefore, an advantage to examine babies in their own cots and preferably shortly after they have been fed.

Ortolani's method-This method is based on the fact that, in babies with dislocation of the hip, gradual abduction of the hip flexed to a right angle causes the dislocated head of femur to slip into the acetabulum with a palpable but not audible click. This "click" is accentuated by exerting slight pressure backwards along the line of the femur as it is abducted, thus displacing the head of the femur more posteriorly. If too much pressure is applied the click may be missed altogether. Next, as the abducted hip is adducted to the midline the head of the femur can be felt dislocating again with a palpable click. It is very important that the hip should not be flexed beyond 90 degrees, or the click may not be felt. The grip used for this examination is similar to that used for Barlow's method.

If the hip is very lax the click of dislocation and reduction may be very slight, and if the examiner is not aware of this laxity as indicated by Barlow's test it would be quite possible to miss the diagnosis. The two tests are therefore complementary.

Early in the series the author was confused by a variety of clicks which were not only palpable but also audible. Most of these arose at the patello-femoral and knee joints, and a few were from the hips but were not due to instability. The "click" of dislocation and reduction in congenital dislocation is inaudible.

\section{RESULTS}

Of the 6,000 babies examined twenty-four were considered to have congenital dislocation of the hip and twenty-three of these were treated in a von Rosen type of splint. Table I shows the number of cases diagnosed each year of the survey and the age of the baby in days at the time of diagnosis.

Sex incidence-As in all other series the incidence of congenital dislocation was far higher in females than in males (Table II).

Side affected-The left hip was involved more often than the right. Of thirty-four affected hips twenty-two were left and twelve were right (Table III).

Race-There was no racial predominance in the incidence of dislocation (Table IV). In China congenital dislocation of the hip is rare, possibly because of the way babies are carried with their hips abducted across the mother's back. Both Chinese babies in this series were full blooded and unrelated.

Presentation-Six of the twenty-four babies (one boy and five girls) presented by the breech. According to Mayes (1950) the normal incidence of breech presentation is one in twenty-five. The higher incidence of hip dislocation in babies presenting by the breech is in accord with the findings of Barlow (1962).

Family history-Two of the twenty-four babies had a family history of congenital dislocation, and in one of these it was strong. Several of the babies with dislocation had normal siblings later but one girl with bilateral dislocation later had a sister who was similarly affected. There was no previous history of dislocation in this family and the first child born was normal.

There is undoubtedly a hereditary factor in congenital dislocation of the hip but this is probably not nearly so strong as has been thought in the past.

Prematurity-Premature babies were not more prone to dislocation than those born at full term.

VOL. 50 B, NO. 3, AUGUST 1968 
TABLE I

Incidence of Congenital Dislocation and Age at Diagnosis

\begin{tabular}{|c|c|c|}
\hline Year & Number of babies & Age of baby in days \\
\hline 1963 & 4 & $5,8,5,4$ \\
\hline 1964 & 12 & $4,1,1,3,5,1,3,3,5,1,5,2$ \\
\hline 1965 & 6 & $1,4,1,4,2,5$ \\
\hline 1966 & 2 & 2,3 \\
\hline
\end{tabular}

TABLE II

Sex InCIDEncE

\begin{tabular}{|c|c|c|}
\hline \multirow{2}{*}{ Year } & \multicolumn{2}{|c|}{ Number of babies } \\
\cline { 2 - 3 } & Female & Male \\
\hline 1963 & 3 & 1 \\
1964 & 11 & 1 \\
1965 & 4 & 2 \\
1966 & 2 & 0 \\
\hline Total & 20 & 4 \\
\hline
\end{tabular}

TABLE III

Side Affected by Congenital Dislocation

\begin{tabular}{|c|c:cc|}
\hline Year & Bilateral & Left & Right \\
\hline 1963 & 0 & 3 & 1 \\
1964 & 5 & 6 & 1 \\
1965 & 3 & 3 & 0 \\
1966 & 2 & 0 & 0 \\
\hline
\end{tabular}

TABLE IV

RACIAL INCIDENCE

\begin{tabular}{|c|c|}
\hline Race & $\begin{array}{l}\text { Number of babies } \\
\text { with hip dislocation }\end{array}$ \\
\hline British . & 16 \\
\hline Maori . & 3 \\
\hline Chinese. & 2 \\
\hline Polish & 2 \\
\hline Dutch . & 1 \\
\hline
\end{tabular}


Associated abnormalities-In only one baby were there other congenital abnormalities in association with dislocation of the hip. This child suffered from arthrogryposis multiplex congenita (Case 5).

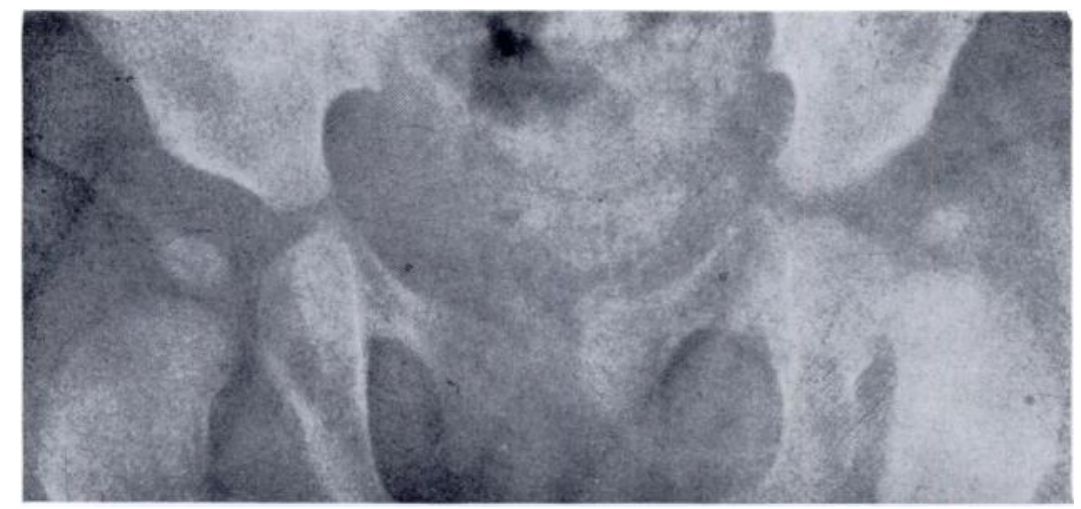

Fig. 1

Congenital dislocation of the left hip. Note that the upper end of the femur is standing out more on the affected side than on the normal side.

RADIOGRAPHY

For the first two years of the survey attempts were made to confirm the clinical diagnosis by radiography. Techniques described by Andrén and von Rosen (1958) were applied but without much success. It was concluded that reliance could not be placed on radiography as a means of diagnosing congenital dislocation of the hip in children under about four months of age. After this age radiography was of great value in following the development of the hips. Particular attention was paid to the slope of the roof of the acetabulum and to the appearance of a beak of bone at the lateral lip of the acetabulum. The position of the upper end of the femur in relation to the acetabulum varied and at times the upper end of the femur appeared to be standing out more than one would expect in a normal hip (Fig. 1).

The time of appearance of the ossific centre varied from six weeks to fifteen months. Little significance can be attached to the late appearance of the ossific centre unless one side lags well behind the other.

\section{METHOD OF TREATMENT}

Of the twenty-four babies in whom the diagnosis of congenital dislocation was made, twenty-three were treated by splintage and one was not treated.

TABLE $\mathrm{V}$

Age at Commencement of Treatment

\begin{tabular}{|c|cc|}
\hline Year & Number of babies & Age of baby in days \\
\cline { 1 - 3 } \cline { 1 - 2 } 1963 & 3 & $4,7,6$ \\
1964 & 12 & $4,10,2,4,5,5,4,8,3,3,2,5$ \\
1965 & 6 & $5,5,6,5,5,8$ \\
1966 & 2 & 6,7 \\
\hline
\end{tabular}

Table $\mathrm{V}$ shows the age of the babies in days at the time of application of the splint. The number of dislocations diagnosed was considerably higher in 1964. It will be noticed that of these twelve babies seven were placed in the splint under five days of age. Later in 


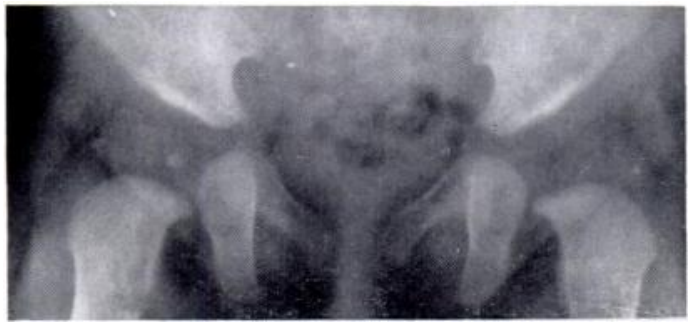

Fig. 2

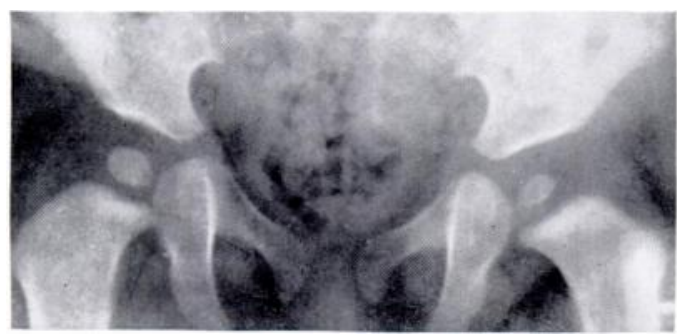

FIG. 4

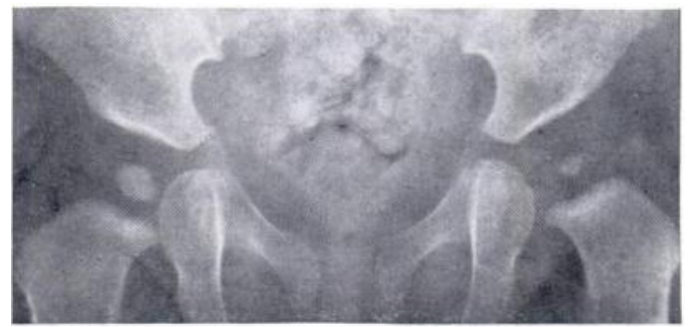

Fig. 3

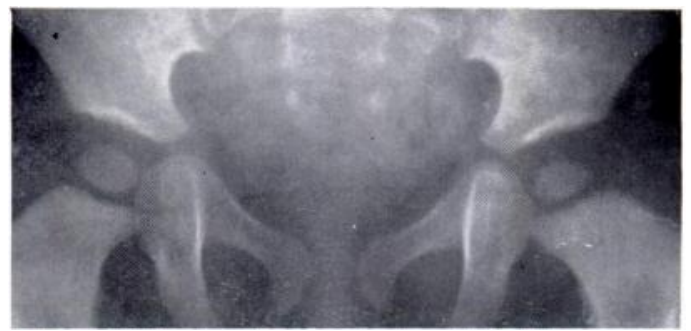

Fig. 5

Congenital dislocation of the left hip. Progress after treatment lasting eight weeks. Figure $2-$ Aged 5 months. Figure 3-Aged 9 months. Figure 4-Aged 12 months. Figure 5-Aged 18 months. The development of the left hip has spontaneously overtaken that of the right.

the survey it was decided to wait until the baby was at least five days old before deciding whether to apply a splint or not. It was found then that the numbers needing treatment were less. This postponement of treatment could be extended further with an even greater reduction in numbers needing treatment. This was done by Stanisavljevic (1964) who found that if he left babies until they were in their second month before treatment started they needed five to eleven months of splintage in order to obtain normal hips.

When it had been decided that a child had congenital dislocation a splint similar in shape to that described by von Rosen was applied. The splint was made of aluminium and covered with polythene. Pressure of the shoulder straps on the mastoid processes was encountered and was corrected by curving the straps away from the neck. After this modification no further difficulties were encountered with the splint. On two occasions the shoulder straps were removed but it was found that the splint slipped, no longer holding the hips abducted.

The splint was removed at three weeks and the stability of the hips checked. In all cases they were found to be stable at this examination. The splint was reapplied. Early in the series it was left on for a further three weeks; later it was left on for five weeks. Apart from these examinations the splint was worn continuously. After removal of the splint no treatment was given and the child was brought back at intervals of four months and later six months for clinical and radiological examination.

\section{RESULTS OF TREATMENT}

The twenty-three treated babies have been followed up for an average of nineteen months with a range from three months to thirty-six months. With the exception of one baby (Case 6) the hips of all these babies have developed satisfactorily and the older babies in the series have been discharged as clinically and radiologically normal (Figs. 2 to 5).

Occasionally the appearances of the hips remained abnormal for some time after treatment had stopped, but ultimately became normal without further treatment (Figs. 6 to 10). 


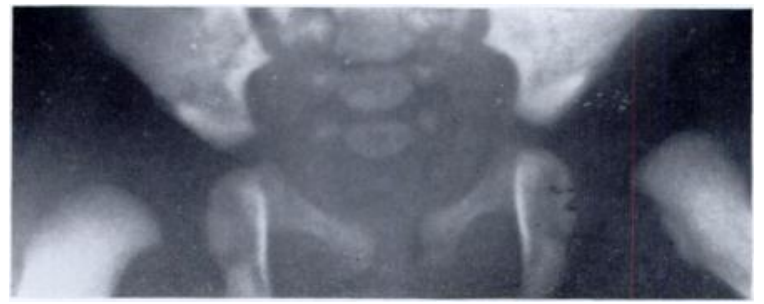

Fig. 6

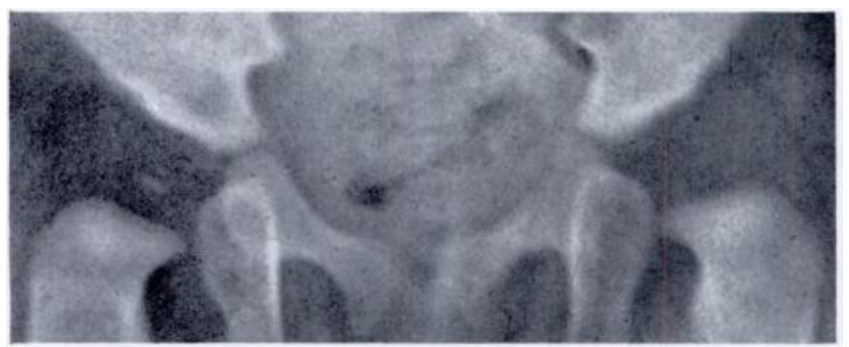

FiG. 7

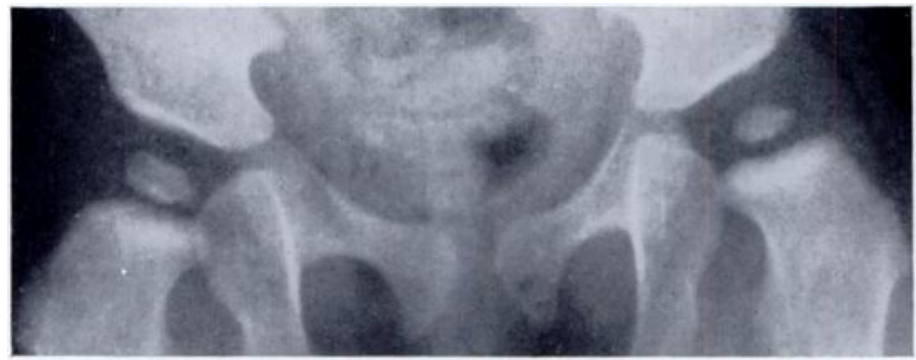

FIG. 8

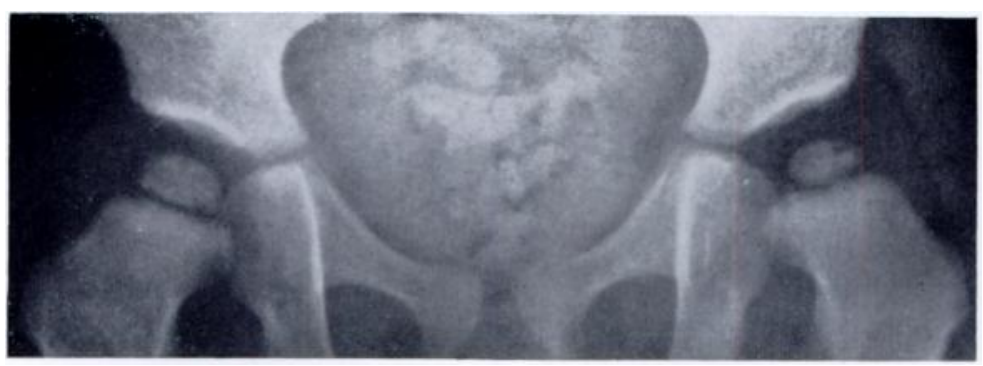

FIG. 9

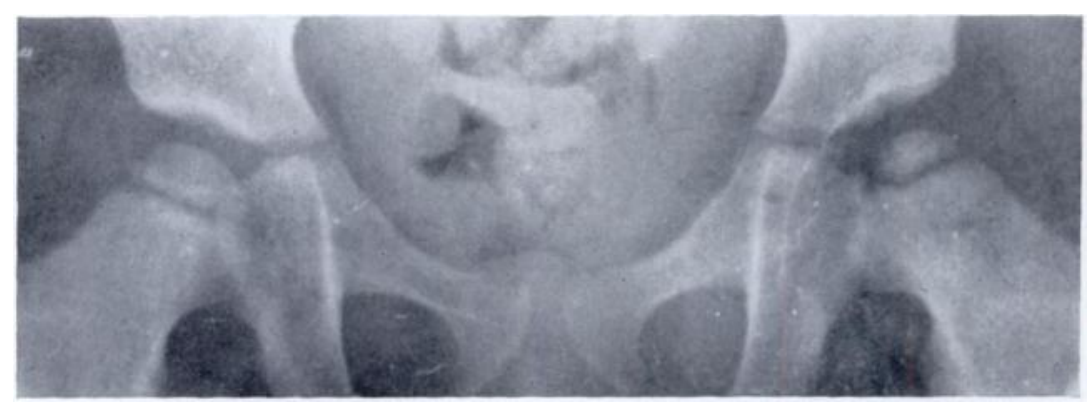

FIG. 10

Congenital dislocation of the left hip. Progress after treatment lasting eight weeks. Figure 6-Aged 4 days. Figure 7-Aged 4 months. Figure 8-Aged 11 months. Figure 9-Aged 17 months. Figure 10-Aged 27 months. The development of the left hip still lags behind that of the right.

VOL. 50 B, NO. 3, AUGUST 1968 


\section{CASES MISSED}

During the period of the survey four babies were born who were passed as normal at birth but who were later found to have abnormal hips.

Case 1-A baby girl, born by breech delivery in the twenty-eighth week of pregnancy, weighed 2 pounds 8 ounces at birth. For the first few weeks there was considerable doubt as to whether she would survive. In view of this, examination of the hips was deferred until she was nearly three weeks old and at that time they were passed as normal. At ten months she was noticed to have asymmetrical skin creases and a clinical diagnosis of dislocation of the left hip was confirmed by radiography. Even at this age her management was complicated by repeated episodes of respiratory infection which delayed reduction and splintage.

Two factors were probably responsible for the failure of diagnosis in this child. Firstly, she was born early in the survey before the author had felt any other newborn babies with dislocated hips. Secondly, the examination was delayed for three weeks, by which time the signs may have no longer been present. Examination of the hips causes so slight a disturbance that it should not be delayed beyond a few days from birth. Owing to the increased difficulty of examining babies in the incubator special care should be taken with premature infants.

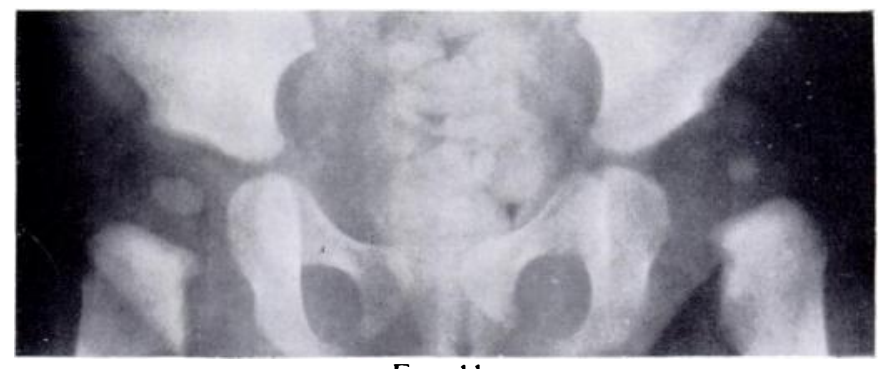

Fig. 11

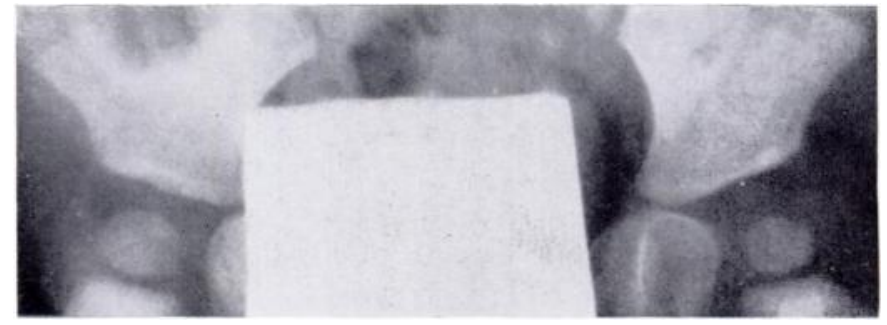

FIG. 12

Case 2-Hips passed as normal at examination soon after birth. Figure 11-Aged 7 months. The head of the left femur stands out in comparison to that of the right. Figure 12-Aged 1 year, after five months in an abduction splint. Both hips appear normal.

Case 2-A girl was first noticed to have asymmetrical skin creases at five months and radiographs indicated that she had subluxation of the left hip (Fig. 11). She was treated in a Jourdon type abduction splint for five months (Fig. 12).

The appearances of this child's hips are not unlike those of some of the children who were treated from birth and which, from a similar stage of development, recovered spontaneously. At the present stage of our knowledge treatment seems advisable but it is possible that these hips would have developed normally without treatment.

Case 3-A girl would not stand at the age of one year. Clinically both hips were normal but a radiograph showed subluxation of the left hip (Figs. 13 and 14). One month later arthrography before treatment started showed that the head of the left femur was well covered by the acetabulum (Fig. 15). She was treated in a "frog " plaster.

As in Case 2 this apparent subluxation may in fact be spontaneously recovering. 


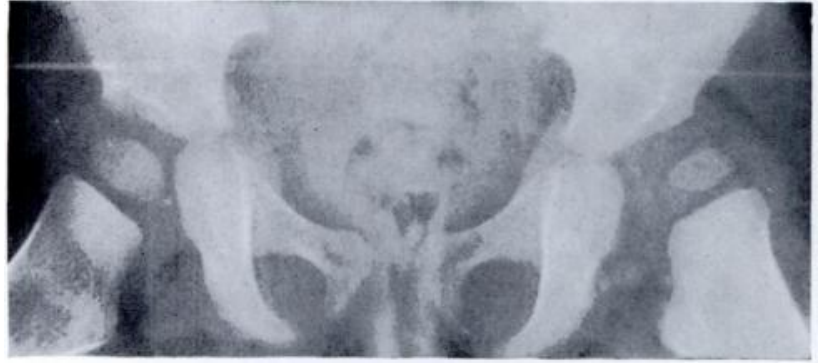

FIG. 13

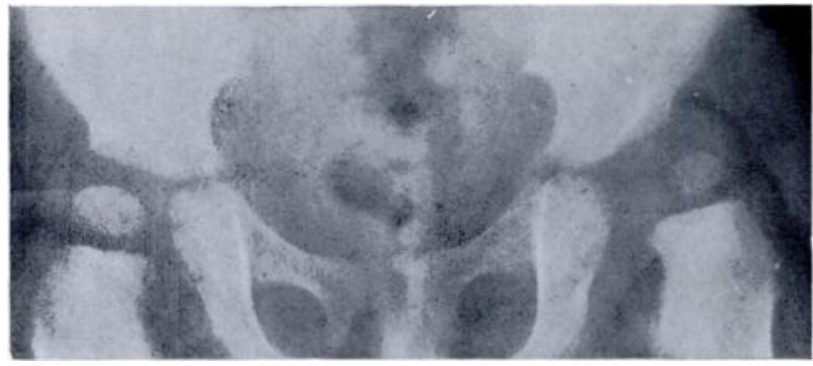

FIG. 14

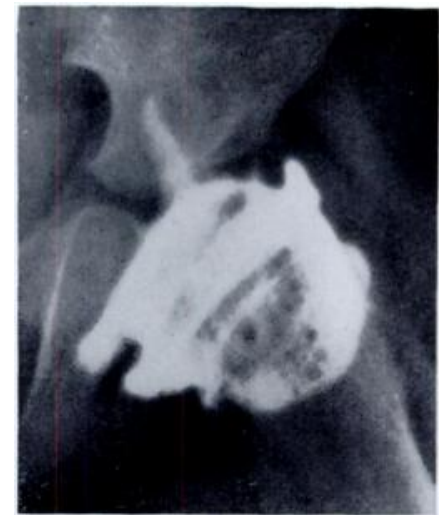

FIG. 15

Figs. 13 To 15

Case 3-Hips passed as normal at examination soon after birth. Figures 13 and 14 Aged 1 year. The head of the left femur stands out

in comparison to that of the right. Figure 15-Arthrographone month later. The head of the left femur is well covered by the acetabulum.

Case 4-A girl was referred when aged nine months because the nurse had noticed asymmetrical skin creases. Clinically the hips were normal but a radiograph showed subluxation of the left hip (Fig. 16). A Jourdon type polythene abduction splint was fitted and worn for seven months, when a radiograph showed both hips to be developing well.
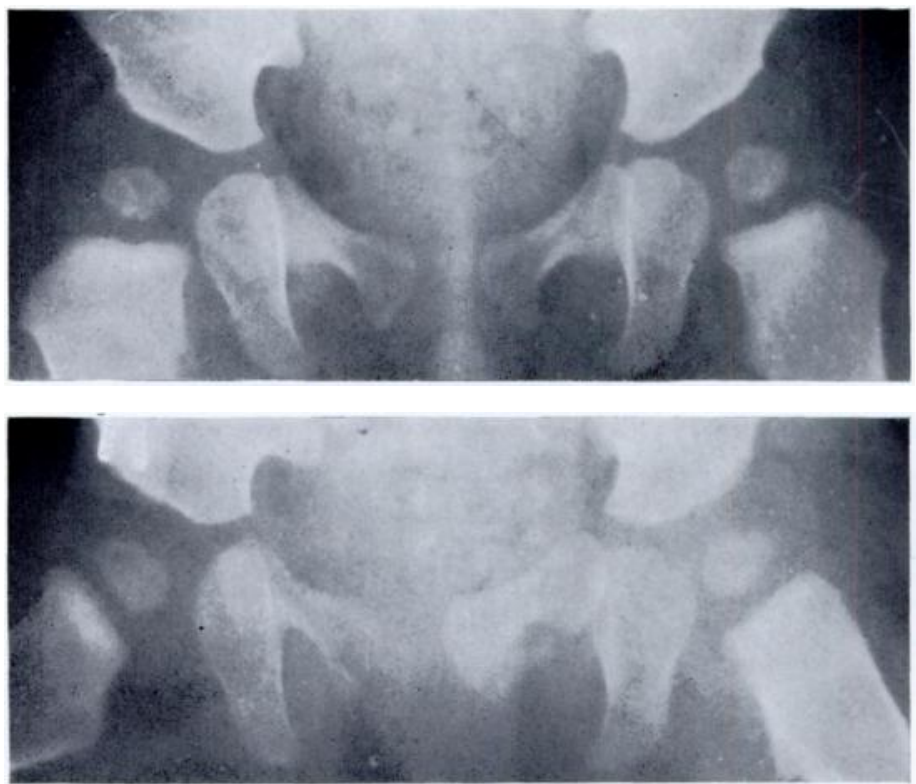

Fig. 16

Case 4-Hips passed as normal at examination soon after birth. At the age of 9 months the head of the left femur stands out in comparison to that of the right.

\section{CASES OF SPECIAL INTEREST}

Case 5-A boy was examined on the third day of life and was found to have multiple deformities including dislocation of the right hip, bilateral club foot and facial asymmetry. It was 
impossible to abduct the flexed right hip more than 40 degrees and there was no apparent instability on Barlow's or Ortolani's tests. Radiographs confirmed the right hip dislocation and later films showed a vertical talus on the right (Figs. 17 and 18). The child was considered to have arthrogryposis multiplex congenita, and in view of the impossibility of reducing the

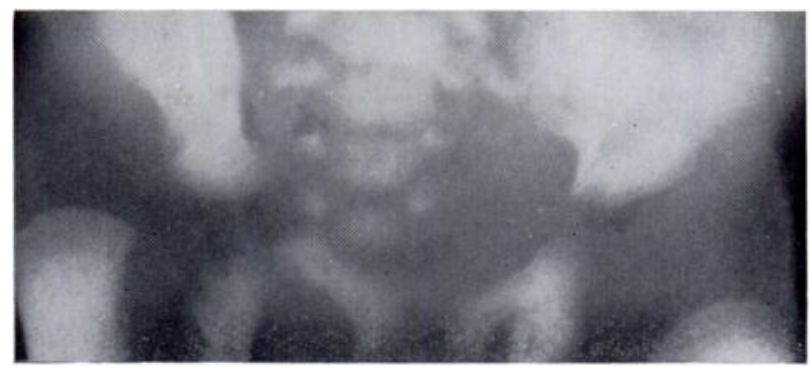

FIG. 17

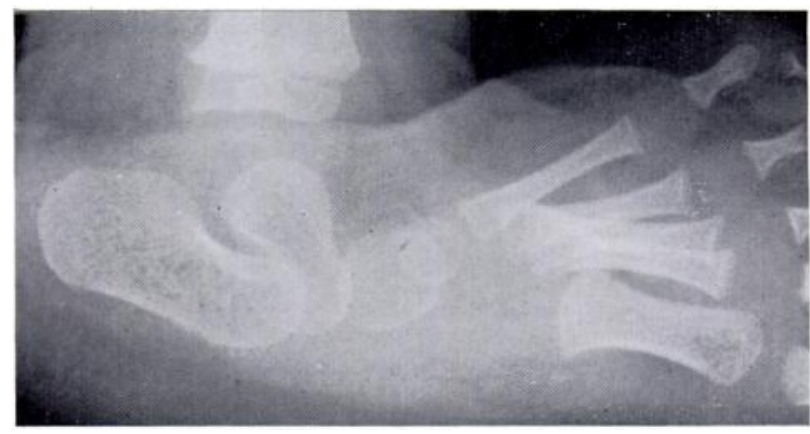

Fig. 18

Case 5-Arthrogryposis multiplex. Figure 17--Dislocation of the right hip. Figure 18-Vertical talus in the right foot.

hip no useful purpose could be seen in splinting it. When the child was older an attempt was made to reduce the dislocation on a Jones abduction frame but this also failed. Arthrography showed a false acetabulum forming on the ilium and under the image intensifier again the head could not be shifted. It was decided to accept the position and not to proceed with open reduction.

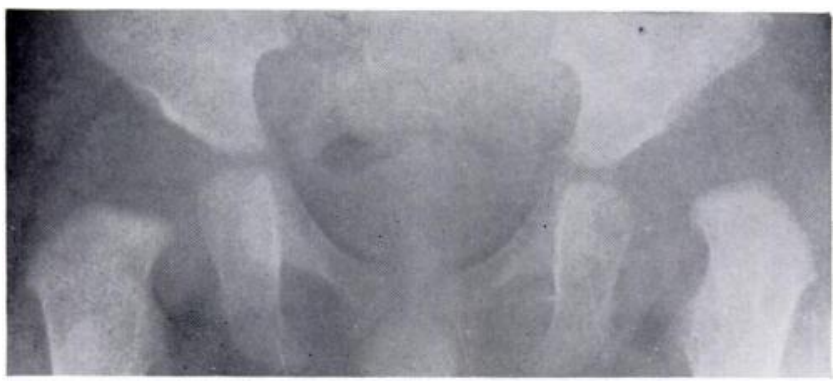

FIG. 19

Case 6- Congenital dislocation of both hips recognised soon after birth and treated by splintage for two months. Redislocation of the left hip at the age of 6 months.

Case 6-This boy was seen on the fourth day of life and was found to have dislocation of both hips. A splint was applied and at examination after three weeks both hips were stable. The splint was continued for a further five weeks and then the child was allowed free. A check radiograph four months later (Fig. 19) showed that the left hip was redislocating. He was 
therefore admitted, and after reduction in a Jones abduction frame a "frog" plaster was applied. After three months in plaster a further radiograph showed the left hip once again dislocated and arthrography showed that the head could not be properly reduced. Open reduction revealed a small limbus, but probably more important was the tendon of psoas stretched tightly across the capsule.

An interesting feature of this case is that there was a strong family history of congenital dislocation of the hips, with ten cases among close relatives. The father and one brother were among those affected.

It is possible that had the splint been retained for a longer period the left hip, like the right, might have remained stable. In the presence of a family history it is probably wise to prolong the time of treatment in the splint.

Case 7-This girl, seen on the third day of life, was found to have bilateral positive Ortolani's signs which were not present when she was re-examined on the seventh day. No treatment was given. At post-natal examination the obstetrician noted that once again both hips were unstable. This was confirmed by the author clinically but radiographs were not helpful in making a diagnosis.

The child was placed in a Jourdon type abduction splint for ten weeks and at the end of that time both hips were clinically stable. A radiograph showed the acetabula to be developing satisfactorily.

\section{UNSTABLE HIPS}

In addition to those babies with congenital dislocation of the hip a number of babies were found to have hips which were either dislocated or could readily be dislocated at birth but which, in the first few days of life, became clinically normal. Earlier in the survey when a hip was found to show Ortolani's sign it was splinted forthwith. Later in the survey the

TABLE VI

Unstable Hips: Age at Time of Diagnosis and Incidence of Ortolanis Sign

\begin{tabular}{|c|c|cc|}
\hline Year & $\begin{array}{c}\text { Number of } \\
\text { unstable hips }\end{array}$ & $\begin{array}{c}\text { Age of baby at time of diagnosis } \\
\text { (days) }\end{array}$ & $\begin{array}{c}\text { Ortolani's sign } \\
\text { present }\end{array}$ \\
\hline 1963 & 1 & 6 & 0 \\
1964 & 15 & $1,1,1,1,1,1,2,7,7,5,2,1,5,1,2$ & 3 \\
1965 & 10 & $2,2,4,1,3,4,1,1,3,3$ & 4 \\
1966 & 1 & 4 & 0 \\
\hline
\end{tabular}

hips were examined a second or third time if they were unstable at birth. It was then found that half of these hips had become stable and did not require treatment. Even hips found frankly dislocated on the day of birth often became perfectly stable within twenty-four to forty-eight hours.

A follow-up of those babies with unstable hips was carried out and eighteen of the twenty-seven could be re-examined and radiographed (Table VI). In all cases the hips were normal clinically and radiologically. Four of the eighteen were found to have asymmetrical thigh skin creases. Barlow noted that a high proportion of babies with asymmetrical skin creases had normal hips. Four of the eighteen followed had presented by the breech-again a higher incidence than normal. The sex ratio and racial distribution was similar to that for congenital dislocation of the hip.

vol. 50 B, No. 3, AUGUST 1968 


\section{DISCUSSION}

A survey of 6,000 newborn babies revealed that 0.85 per cent had abnormal hips and that until a few days had elapsed it was not possible to tell which of these children had congenital dislocation and which without treatment would become perfectly normal. Of the female babies 1.4 per cent had abnormal hips at birth, and if the baby presented by the breech the figure rose to $4 \cdot 7$ per cent.

According to Mayes (1950) the reason for a breech presentation cannot often be found. Among possible causes he lists contracted pelvis, prematurity, twins, hydramnios, placenta praevia, hydrocephalus and tumours of the pelvis. None of these except perhaps contracted pelvis seems to be a likely cause of hip dislocation. Beck (1951) pointed out that only 1.7 per cent of full term deliveries are from breech presentations and that the usual figure of 3.5 per cent for breech presentation includes a high proportion of premature babies. Since prematurity was not an important factor in those babies with dislocated hips, the incidence of hip abnormality in full term female babies presenting by the breech could be as high as 9.8 per cent.

The manner of delivery of these babies presenting by the breech and having abnormal hips did not seem to matter-several were, in fact, delivered by Caesarean section.

The rapid stabilisation of many of these hips after birth points to some factor which is quickly eliminated. Andrén and Borglin (1961) noted disturbance of the pattern of oestrogens in the urine of newborn children with hip instability. They did not make clear in their paper whether those babies with abnormal excretion patterns in fact had true congenital dislocation or whether they were babies with unstable hips which might or might not have corrected spontaneously if left untreated. On the first day of life it is not possible to tell the difference.

Stanisavljevic (1964) dissected 300 hips of 150 infants and detected hip pathology in twelve hips of eight infants ( 5 per cent). These twelve hips all showed Ortolani's sign or marked instability. It is presumed that if all these babies survived (many were premature) most of the hips would spontaneously have become corrected (Stanisavljevic found that only 0.58 per cent of the 6,000 babies he examined had abnormal hips). It is interesting to note that he examined babies from two to six days old. In my series of unstable hips eleven of the twentyseven were detected on the first day of life; most of these were normal by the second day and would have been missed by Stanisavljevic.

The hereditary factor which, taken overall, is not prominent but which in certain families is very strong, is probably responsible for gross anatomical changes in the hips rather than for influencing the oestrogen metabolism, though this may play a part. In Case 6 there was no response to treatment as in other cases of congenital dislocation. The right hip remained reduced after routine splintage but the left redislocated twice.

Further study is needed to determine why the hips of one baby become stable spontaneously while those of another remain unstable and if not treated present later as classical cases of congenital dislocation. It is possible that the increased ligamentous laxity produced by excessive levels of oestrogens together with pressure from the abnormal breech presentation is responsible for the instability of the babies' hips at birth. Stanisavljevic (1964) showed that in four or five month foetuses there may already be quite gross pathological changes in the hips that could not be attributed to pressure from the breech presentation. Perhaps the cause is a combination of many factors. In the meantime a method of diagnosing hip dislocation in the newborn is available and in the hands of an experienced examiner is very reliable.

During the course of this survey many doctors and medical students were instructed in the technique of examining the hips of newborn babies. It became obvious that if congenital dislocation was not to be missed this examination would have to be carried out regularly by one or two people rather than by a multitude of obstetricians all examining their own babies. Some of those instructed in the technique became very proficient and detected abnormalities in babies at hospitals other than the one at which this survey was carried out. Others were unable consistently to detect abnormalities. During the course of this survey fifty-one babies 
were seen with abnormal hips but on only four occasions did the obstetrician detect the abnormality. There is no doubt that it is only by examining large numbers of babies that one becomes proficient.

A register of all babies born in a maternity unit should be kept and a doctor experienced in the examination should record whether the hips are normal before the child is discharged. Since congenital dislocation of the hip is treated by orthopaedic surgeons, the proper person to diagnose it is also the orthopaedic surgeon, otherwise he will not have sufficient experience of the feel of normal hips to judge the progress of his treatment. It must be emphasised that the diagnosis and management of congenital dislocation of the hip in newborn babies is dependent on feel and only later do radiographs play a part.

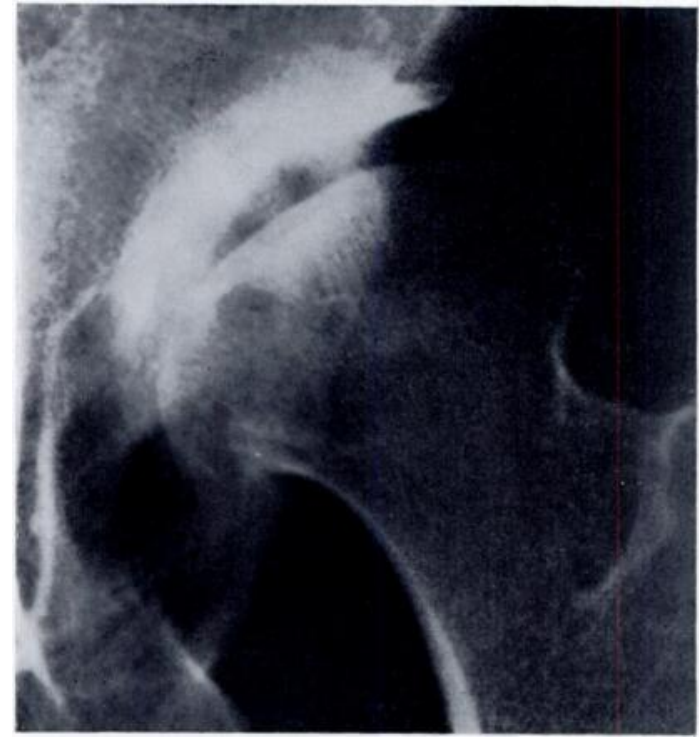

Fig. 20

Osteoarthritis of the left hip at the age of 25 years after unrecognised subluxation.

An analysis of the hips "missed" shows a group of children whose hips are clinically normal at birth but who later develop subluxation. Some of these hips are detected early in life but it is likely that other children lead normal lives until osteoarthritis develops (Fig. 20). If they are seen early their treatment is relatively simple and the results good. Only one case of congenital dislocation of the hip was missed and this was because the baby was not seen early enough and because the examiner at that stage of the survey was not sufficiently experienced.

\section{SUMMARY}

1. Six thousand consecutive newborn babies were personally examined by the author for congenital dislocation of the hip. Twenty-four cases were diagnosed and twenty-three treated. 2. Twenty-two of the twenty-three treated cases had excellent results after treatment in the von Rosen splint.

3. The baby should be five days old before a final decision is made as to whether treatment is necessary.

4. A further twenty-seven babies were found to have unstable hips. Eighteen of these were followed up and all were found to have developed normally without treatment.

5. The technique of examination is simple and quick but it is desirable that it should be carried out in each maternity unit by only one or two doctors.

vOl. 50 B, No. 3, AUguSt 1968 


\section{REFERENCES}

ANDrén, L., and Borglin, N. E. (1961): Disturbed Urinary Excretion Pattern of Oestrogens in Newborns with Congenital Dislocation of the Hip. Acta Endocrinologica, 37, 423.

Andrén, L., and von Rosen, S. (1958): The Diagnosis of Dislocation of the Hip in Newborns and the Primary Results of Immediate Treatment. Acta Radiologica, 49, 89.

Barlow, T. G. (1962): Early Diagnosis and Treatment of Congenital Dislocation of the Hip. Journal of Bone and Joint Surgery, 44-B, 292.

BeCK, A. C. (1951): Obstetrical Practice. Baltimore: Williams \& Wilkins.

Mayes, B. T. (1950): A Textbook of Obstetrics. Sydney: Australasian Publishing Co.

Ortolani, M. (1937): Un segno poco noto e sua importanza per la diagnosi precoce di prelussazione congenita dell'anca. Pediatria, 45, 129.

Rosen, S. von (1962): Diagnosis and Treatment of Congenital Dislocation of the Hip Joint in the New-born. Journal of Bone and Joint Surgery, 44-B, 284.

Stanisavluevic, S. (1964): Diagnosis and Treatment of Congenital Hip Pathology in the Newborn. Baltimore: Williams \& Wilkins. 